Article

\title{
A Creative Analysis of Factors Affecting the Landscape Construction of Urban Temple Garden Plants Based on Tourists' Perceptions
}

\author{
Yang Zhao *, Junhan Liu and Yuqing Chen
}

check for

updates

Citation: Zhao, Y.; Liu, J.; Chen, Y. A Creative Analysis of Factors Affecting the Landscape Construction of Urban Temple Garden Plants Based on Tourists' Perceptions. Sustainability 2022, 14, 991. https://doi.org/ $10.3390 /$ su14020991

Academic Editors: Marc A. Rosen, Kelvin K.L. Wong, Simon Fong, Yu Lu and Dhanjoo N. Ghista

Received: 29 November 2021 Accepted: 13 January 2022

Published: 17 January 2022

Publisher's Note: MDPI stays neutral with regard to jurisdictional claims in published maps and institutional affiliations.

Copyright: (C) 2022 by the authors. Licensee MDPI, Basel, Switzerland. This article is an open access article distributed under the terms and conditions of the Creative Commons Attribution (CC BY) license (https:// creativecommons.org/licenses/by/ $4.0 /)$.
School of Fine Arts, Huaqiao University, Quanzhou 362000, China; fezliu@outlook.com (J.L.); hellochenyuqing@outlook.com (Y.C.)

* Correspondence: 13678@hqu.edu.cn

\begin{abstract}
This study was based on the perspectives of tourists, with data obtained through a questionnaire survey of users of the Kaiyuan Temple Scenic Area in Quanzhou City, Fujian Province, China. Through statistical evaluation and principal component analysis, the data collected from 351 questionnaires were analyzed, and five common factors affecting tourists' perceptions were obtained: spatial structure, functional structure, utility plants, heritage characteristics and sensory characteristics. Through data analysis and research, the following conclusions were drawn: (1) most tourists have high expectations in terms of the overall layout of the temple garden plant landscape; (2) they like eye-catching and interesting plants and comfortable spaces for recreation and leisure; (3) they pay attention to the health-giving properties of plants; (4) tourists like it when the temple garden plant landscape includes a diverse range of plant forms while maintaining distinctive regional characteristics; and (5) tourists find bright flowers and aromatic plants relaxing and mood-enhancing, functioning to promote interaction between the temple landscape and tourists. The findings of the study can therefore be used as theoretical guidance for the design of urban temple garden plant landscape construction that meets the needs of tourists.
\end{abstract}

Keywords: urban temple garden; plant landscape; Quanzhou; principal component analysis

\section{Introduction and Background}

As an important part of the urban green-space system, urban temple gardens are a form of non-renewable wealth, an inheritance of special historic value. Compared with mountain and forest temple gardens, urban temple gardens are closer to home and convenient to use, and they have become one of the most frequently used kinds of urban green spaces in the daily life of residents and tourists [1]; places that are conducive to daily leisure activities, faith activities and improvement of the urban ecological environment. The second feature associated with humanized plant landscapes is the practice of evaluating the quality of urban temple landscapes within the environment [2]. Plants are not only one of the four major elements of a garden landscape [3], but also the main element when it comes to constructing an urban temple landscape. In addition, plants can play a role in "greening up" and beautification, and can also divide and strengthen spaces, helping to set the atmosphere in urban temple gardens, which can directly affect the experience of tourists [4].

The earliest research into Chinese traditional gardens can be traced back to the description of Chinese gardens in "The Travels of Marco Polo". Early Western scholars clarified the study of ancient oriental gardens in books such as "A Study of Oriental Gardens" by William Chambers in 1772 [5], "France and China in the 18th Century" by Cordier Henri in 1910 [6], and "The Chinese Garden: History, Art and Architecture" by Maggie Keswick in 1978 [7]. On a more comprehensive and systematic level, Marianne Beuchert, a famous German horticulturalist, investigated and analyzed the characteristics, history and culture of northern 
imperial gardens and Suzhou gardens in her book "Chinese Gardens". Research into temple gardens in China started relatively late, but, with scholars' attention to China's traditional culture, improvements in academic thought and the development of the garden business, research into temple gardens is gradually increasing. The research direction mainly focuses on architecture, humanistic history and temple garden environments. In architecture, indepth research has been carried out into architectural design and spatial composition in temple gardens [8,9]. Liang Sicheng, Wang Shiren and others have systematically studied the detailed design, specific structure, material selection and construction technology of the temple gardens [10]. The book "Styles and Schools" by Zhuang Yuguang provides a large number of detailed cases and theoretical studies on the evolution of the architectural styles of temple gardens in India, Japan, Africa and Southeast Asian countries [11] from the perspective of humanity and history, and the "religious", "humanistic", "landscape" and "natural" characteristics of Chinese temple gardens have been expounded [12]. In terms of a temple garden environment, Zhao Guanghui analyzed the layout rules and treatment methods of ancient garden architecture and landscapes in "The Garden Environment of Chinese Temples" [13]. On the whole, there is no analysis of the construction of temple garden plant landscapes from a user's point of view.

Plants, as an important part of any garden, provide both the means and materials for garden construction. Plants are not only significant in terms of production and life but also in terms of aesthetics and art. Due to differences in natural conditions and other complicated factors, the utilization of garden plants in Western countries has taken a completely different development direction, and has dramatically different characteristics from those of China. Roberto Burle Marx once said that "we live in a time in which an ever-increasing number of people inhabit metropolitan areas. As garden designers, we must focus our attention on the city, where human beings are cut off from nature and have a greater need to interact with plants" [14]. Plants, therefore, not only have simple biological properties but are also part of the art of gardening. Early research on plants in foreign countries was mainly distributed in natural sciences, medicine, agronomy and other disciplines, including the "Historia Plantarum" [15] by the ancient Greek scientist Theophrastus, "De materia medica" by Dioscorides and Cato's "Agriculture Chronicles". These works contain a lot of plant varieties and forms, and provide key clues for the study of the use of garden plants at this point in history. Descriptions of garden plants can also be found in classical literature, such as the ancient "Bible" and "Koran", which mention a variety of plants. Similarly, there are many descriptions of plants in the "Gilgamesh Epic" and "Odyssey" of Homer, which reflect the description and depiction of plants while telling literary stories. As for modern scientific and systematic studies, these are all general works in the history of Western gardens. The British landscape designer Penelope Hobhouse's "Plants in the History of Gardens" describes changes in the use of plants during the development of Western gardens, in chronological order. Dusan Ogrin's “World Garden Heritage" and Linda Farrar's "Ancient Gardens and Gardeners" consider different periods of application of Western garden plant characteristics, where Western garden plants have had an important influence on both development and application.

Generally speaking, plants are an important part of gardens and provide important materials for building gardens. At the same time, the plant landscape also plays an important role in the construction of temple garden space in different respects, as follows:

(1) A contrasting effect: temple architecture is usually integrated with nature, so that the configuration of garden plants and buildings is a fusion of natural beauty and artificial beauty. The rich colors of plants and soft and changeable lines are matched with the solemnity of temple buildings, which adds to the beauty of each building and enhances the religious atmosphere. In the incense road of the temple and the courtyard of the main hall, tall trees are often grown, with thick crowns, and ancient and traditional trees or trees with religious associations are cultivated to reflect the simple and religious meanings of the temple. The relationship between temple architecture and plants is not only mutually supportive and complementary, but also a fusion of life and divinity; a concrete 
manifestation of the idea of harmony between man and nature, and an integral whole within the temple's cultural landscape.

(2) Spiritual sustenance: temples enshrine many religious doctrines and myths which are related to plants. According to legend, Sakyamuni sat quietly for seven days and seven nights under the Buddha's Bodhi tree. He suddenly became enlightened and became a Buddha. Therefore, the Bodhi tree became the sacred tree of Buddhism, and one of the indispensable tree species in temples. The "five trees and six flowers", "four sacred trees" and "four lucky flowers" in Buddhism are common in most temples, and these are usually plants related to the Buddha. They are all regarded as the incarnation of the Buddha and have become an object of worship.

(3) Ornamental effect: since the Song Dynasty, religious activities have gradually become richer and more colorful, attracting large numbers of literati and ordinary people alike, keen to visit such temples. At the same time, the nature of religious activities has also undergone great changes, from single acts of worship to appreciation and cultural dissemination activities. Those responsible for temples therefore began planting large numbers of precious flowers and trees for people to look at while walking, reciting poetry or painting, inspiring and uplifting them. This was a big step forward. Temple guardians began paying attention to the selection and configuration of garden plants, and began building beautiful garden landscapes to meet the needs of people in terms of worship, as well as leisure.

(4) Production effect: most temple sites are located in mountains and forests, far away from urban areas (similar to an independent manor), where monks lead basic and self-sufficient lives. Devadado, a disciple of Shakyamuni, advocated vegetarianism. After it was introduced into China, the canon prohibited monks from consuming meat, so the monks depended on plant food for subsistence. Therefore, some edible plants were planted near temples, such as bamboo, tea trees and February blue, etc., gradually forming temple gardens, with various functions, e.g., as flower gardens, fruit gardens, medicinal gardens and vegetable gardens.

Based on ecology, environmental psychology and artistic composition theory, combined with basic theories of garden planting design and other theories, this study examined Kaiyuan Temple in Quanzhou City, Fujian Province, China. A mathematical analysis method was used, based on subjective and objective evaluation of the garden plant landscape, establishing a scientific weight evaluation index system and an evaluation model of the garden plant landscape. Through optimization of the role of the garden plant landscape in environmental construction, the power of plant landscape design can be used to serve people. It can also provide a point of reference for the development of temple garden plant landscapes in the future.

\section{Materials and Methods}

\subsection{Subjects}

Kaiyuan Temple in Quanzhou was built in the second year of Lugong of Wu Zetian in the Tang Dynasty (686 AD). It is located in West Street, Licheng District, Quanzhou City, Fujian Province, China, and covers an area of 78,000 square meters. It has a subtropical monsoon climate, with an average annual temperature of $17-21^{\circ} \mathrm{C}$ and an average rainfall of 1400-2000 mm. Kaiyuan Temple in Quanzhou is the largest Buddhist temple in Fujian Province [16], as well as being an important cultural relic and historic site on the southeast coast of China. It is one of the most representative urban temple gardens in China, integrating religious activity sites, cultural relic protection units and scenic historic spots [17].

The overall layout of Kaiyuan Temple is different from other traditional temples, mainly imitating the Seven Tang Jialan of the Tang Dynasty (Figure 1). The main buildings of the Kaiyuan Temple are arranged on the central axis and are divided into three parts: the middle part is the Buddhist temple building area, and the east and west wings are garden areas, each with its own tower in the center. In the architectural area of the Buddhist temple, the buildings appear in the form of groups, sitting north and facing south, centered on the 
Daxiong Hall and arranged on the axis of three clusters of courtyards. In the central axis group is the main hall of the temple, running from south to north, followed by Ziyunping, Tianwang Hall, Daxiong Hall, Ganlu Jietan, the Tibetan Scripture Pavilion and Zu Hall. The main halls are separated from one another. Daxiong Hall and Ganlu Jietan form a courtyard with two entrances and corridors on both sides. In the axis group, on the east side is Wuguan Hall and Gongde Hall, and on the west side is the Tanyue Temple. In the northwest group are located guest halls, tourist service centers, nursing homes and some monks' houses. The memorial hall of Master Zhonghongyi and Bunshengin in the eastern group has independent courtyards. The east and west towers, which are important religious and spiritual buildings of the temple, are far away from the main buildings and are placed in the east and west garden areas (see Appendix A Figure A1).
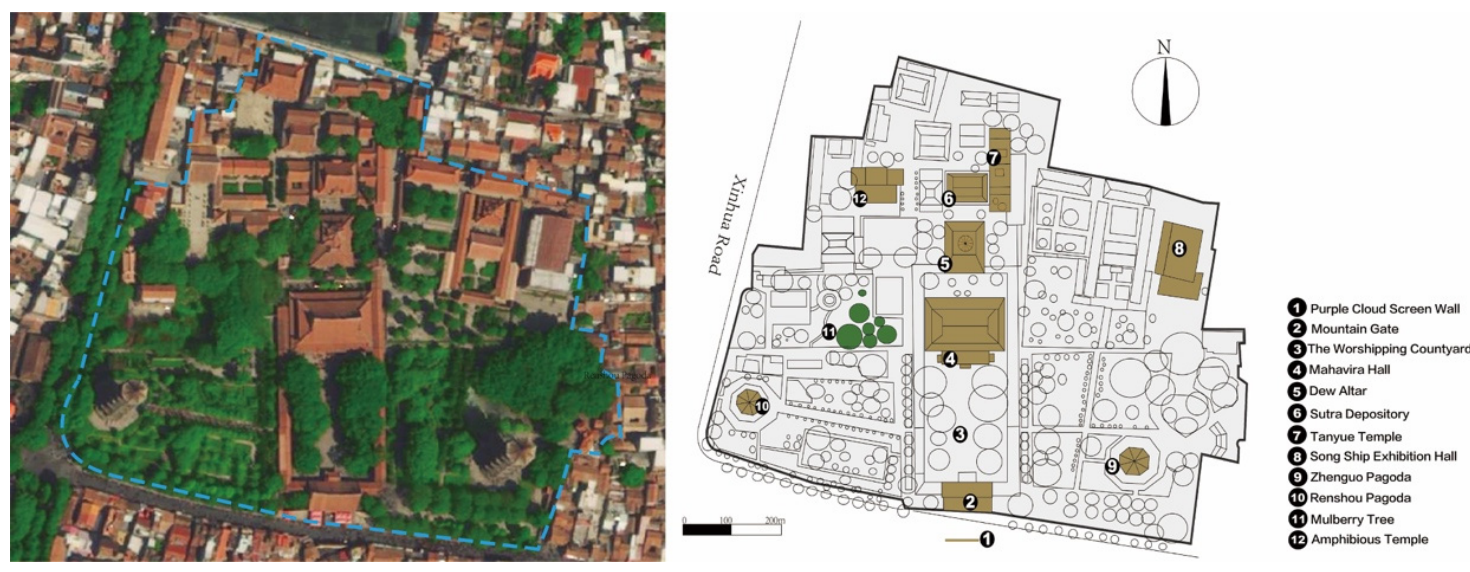

Figure 1. Layout of Kaiyuan Temple.

A relatively large number of subtropical climate plants have also been planted in the Kaiyuan Temple, which are in line with local regional characteristics, such as linden trees and camphor trees. There are also fruit trees in Quanzhou, such as mangoes, longan trees, papaya, shrubs, sweet-scented osmanthus, jasmine, Ligustrum lucidum, Mi Zilan and Michelia lucidum, etc. All adopt a combination of community, cluster planting or patch planting, as a whole, to match the axis layout of the building and to avoid landscape differences. Whether it is a thousand-year-old mulberry tree or an ancient banyan tree on both sides of the road, the meticulously thought-out planting marks the religious atmosphere of the Kaiyuan Temple, and the distribution of different types of plants increases the gardens' interest and visitors' appreciation of this Buddhist temple environment (see Appendix B Figure A2).

\subsection{Data Source and Pretreatment}

\subsubsection{Identification of Alternative Indicators}

With the continuous enhancement of tourists' subjective consciousness, tourists tend to be the main users of garden landscapes [18]. With the aim of capturing tourists' perceptions, this study followed the principles of systematicness and scientificity, representativeness and comprehensiveness, independence and stability, operability and practicality, which are reflected in the combined characteristics of the plant landscape of the Kaiyuan Temple, and which demonstrate how to create a good plant landscape.

Thirty evaluation items were preliminarily determined based on the characteristics of urban temple gardens and tourists' perceptions of plant landscape features, as well as a literature review and field interviews, as follows: ancient and famous trees; flowering plants; growth of plants; leafy plants; the seasonal phase of plants; fruit-bearing plants; the perspective of plant space; climbing plants; the health-giving properties of plants; exotic plants; fragrant plants; native plants; the specificity of plant leaf shapes; edible plants; medicinal plants; plant space-separation functions; plants providing shade; wind resistance 
of plants; plants with cultural significance; the persistence of plant effects; the color of plants; a planting layout that creates a sense of layers; stability of plants; diversity of plant species; coordination between plants and the surrounding environment; visible greenery; the texture of plants; creation of spaces and shapes; a sense of space and openness; and the richness of plant contours. These 30 index factors were then used to design an expert questionnaire (see Appendix C).

\subsubsection{Identification of Evaluation Indicators}

The Delphi method was adopted in our research, i.e., the collection of data relating to the participants' personal experience and the knowledge of each invited expert, via a certain means, to form a collective wisdom and to facilitate appropriate analysis and an evaluation of the key factors. The Delphi method emphasizes structured, anonymous communication between individuals who have expertise in a certain area, with the goal of arriving at a consensus in areas of policy, practice or organizational decision-making [19]. The Delphi method was used to ask 20 industry experts to score the above indicators, so that their opinions could be sought. A Likert five-point scale was used to measure the evaluation items [20], as follows: strongly agree, agree, neutral, disagree and strongly disagree; recorded as 5 points, 4 points, 3 points, 2 points and 1 point, respectively. Finally, 18 different evaluation items were determined: $\mathrm{X} 01$ has ancient trees and famous trees; $\mathrm{X} 02$ has leafy plants; X03 has flowering plants; X04 has fruit-bearing plants; X05 has climbing plants; $X 06$ has exotic plants; $X 07$ has fragrant plants; $X 08$ has native plants; $X 09$ has edible plants; $X 10$ has medicinal plants; $X 11$ has plants with a space-separating function; $X 12$ has plants providing shade; X13 has plants with cultural significance; X14 has a planting layout that creates a sense of layers; X15 has plant species diversity; X16 coordinates plants with the surrounding environment; $X 17$ creates spaces and shapes; $X 18$ has a sense of space and openness (Table 1).

Table 1. Evaluation items for the urban temple garden landscape.

\begin{tabular}{|c|c|c|c|}
\hline Evaluation Item & Project Name & Evaluation Item & Project Name \\
\hline X01 & $\begin{array}{l}\text { Ancient and } \\
\text { famous trees }\end{array}$ & $\mathrm{X} 10$ & Medicinal plants \\
\hline $\mathrm{X} 02$ & Leafy plants & $\mathrm{X} 11$ & $\begin{array}{l}\text { Plants with } \\
\text { a space-separating function }\end{array}$ \\
\hline $\mathrm{X} 03$ & Flowering plants & $\mathrm{X} 12$ & Plants providing shade \\
\hline X04 & $\begin{array}{l}\text { Fruit-bearing } \\
\text { plants }\end{array}$ & $\mathrm{X} 13$ & Plants with cultural significance \\
\hline X05 & Climbing plants & $\mathrm{X} 14$ & $\begin{array}{c}\text { A planting layout that creates } \\
\text { a sense of layers }\end{array}$ \\
\hline X06 & Exotic plants & X15 & Plant species diversity \\
\hline X07 & Fragrant plants & X16 & $\begin{array}{l}\text { Coordination between } \\
\text { plants and the } \\
\text { surrounding environment }\end{array}$ \\
\hline $\mathrm{X} 08$ & Native plants & $\mathrm{X} 17$ & Creation of spaces and shapes \\
\hline X09 & Edible plants & X18 & Sense of space and openness \\
\hline
\end{tabular}

After incorporating the 18 selected indicators into the urban temple landscape evaluation table (taking into consideration the weather and traffic conditions), the survey activities were conducted every other weekday, between 9:00 and 12:00 in the morning and 3:00 and 6:00 in the afternoon, respectively. The survey locations were near the main buildings in the Kaiyuan Temple. In total, 400 questionnaires were issued, and 351 valid questionnaires were obtained, with an effective rate of $87.8 \%$. We then calculated and analyzed the survey results (see Appendix D). 


\subsection{Methods}

SPSS software facilitates analysis of complex survey data, including stratification, clustering, multi-stage and weight [21]. Factor analysis involves studying the relationship between variables and generalizing these into a few factors that are easy to understand and reflect the topic being investigated [22]. SPSS software was successfully developed by Norman H. Nie, C. Hadlai (Tex) Hull and Dale H. Bent of Stanford University in 1968 and acquired by IBM in 2009. With the help of the factor analysis function of SPSS 22.0 verison, we extracted the factors affecting evaluation of an urban temple garden plant landscape from 18 evaluation items, and discussed and analyzed each factor in relation to the actual situation.

Principal component analysis (PCA) is the most popular technique for interpreting large datasets, reducing the dimensionality in an interpretable way, without losing important information in the data [23]. The advantage of the principal component analysis method is that it can simplify complex problems, reduce the dimensions of multiple impact factors involved in the problem, and grasp the main contradictions, so as to better explain the correlation between key variables. The PCA method was used in this study to analyze the preselected influencing factors, to determine the evaluation indicators that affect the urban temple garden plant landscape, and to obtain the weight of each evaluation index; thereby, contributing to the sustainable development of urban temple gardens.

\section{Results}

\subsection{Characterization of Samples}

The field investigation and analysis indicated that the gender ratio of the park activity group was about 1:1, with participants mainly in the 18-59-year-old age group, of whom those aged 18-44 years accounted for $31.05 \%$ of the total sample; middle-aged people between 45 and 59 accounted for $23.36 \%$ of the tourists; those aged between 60 and 74 years old accounted for $21.65 \%$ of the total sample; and those aged over 75 years (who generally had more leisure time) accounted for $17.38 \%$ of the total sample. Most of the survey groups came to the scenic area of the Kaiyuan Temple in Quanzhou for the purpose of experiencing religious culture, conducting faith activities and enjoying the historic landscape (see Table 2).

Table 2. Summary statistics for sample characteristics.

\begin{tabular}{llll}
\hline Project & Option & Frequency & Proportion \\
\hline \multirow{2}{*}{ Gender } & Male & 160 & $45.58 \%$ \\
& Female & 191 & $54.42 \%$ \\
Age & Under the age of 18 & 23 & $6.55 \%$ \\
& $18-44$ & 109 & $31.05 \%$ \\
& $45-59$ & 82 & $23.36 \%$ \\
Visiting frequency & $60-74$ & 76 & $21.65 \%$ \\
& 75 year old or over & 61 & $17.38 \%$ \\
& Twice a week or more & 87 & $24.79 \%$ \\
& Once a week & 95 & $27.07 \%$ \\
Mode of & Once a month & 107 & $30.48 \%$ \\
transportation & Hardly ever & 62 & $17.66 \%$ \\
& Bus & 83 & $23.65 \%$ \\
& Bicycle, electric bike & 73 & $20.80 \%$ \\
& Walking & 64 & $18.23 \%$ \\
Distance from home & 79 & $22.51 \%$ \\
& Private cars & 52 & $14.81 \%$ \\
& Taxi & 30 & $8.55 \%$ \\
& Within 1 km & 109 & $31.05 \%$ \\
& 1-3 km & 126 & $35.90 \%$ \\
& 3-5 km & 86 & $24.50 \%$ \\
\hline
\end{tabular}


Table 2. Cont.

\begin{tabular}{llll}
\hline Project & Option & Frequency & Proportion \\
\hline & To experience religious culture & 144 & $41.03 \%$ \\
& Course learning & 79 & $22.51 \%$ \\
Purpose of visit & Worship activities & 205 & $58.40 \%$ \\
(multiple choice) & To enjoy the historic landscape & 286 & $81.48 \%$ \\
& For the scenery & 67 & $19.09 \%$ \\
& Other & 51 & $14.53 \%$ \\
& Family member & 169 & $48.15 \%$ \\
Companion & Friend & 302 & $86.04 \%$ \\
(multiple choice) & Tour group & 76 & $21.65 \%$ \\
& Alone & 204 & $58.12 \%$ \\
& Other & 98 & $27.92 \%$ \\
\hline
\end{tabular}

\subsection{Reliability and Validity Test of the Questionnaire}

The Cronbach alpha coefficient for this study was 0.823 , which is greater than 0.7 (Table 3), indicating that the questionnaire had high reliability. The overall KaiserMeyer-Olkin (KMO) for the questionnaire was 0.841 , significantly greater than 0.7 (Table 4), indicating that there were sufficient samples, and it was suitable for factor analysis. The Bartlett sphericity test found that the significance was 0.000 , significantly less than 0.05 , indicating that there was a correlation between each item, and it could be used for principal component analysis [24].

Table 3. Reliability statistics.

\begin{tabular}{ll}
\hline Cronbach's Alpha & Number of Terms \\
\hline 0.823 & 18 \\
\hline
\end{tabular}

Table 4. KMO and Bartlett tests.

\begin{tabular}{lll}
\hline KMO Sampling Suitability Quantity & & $\mathbf{0 . 8 4 1}$ \\
\hline & Chi-square last read & 1340.757 \\
Bartlett's sphericity test & Degrees of freedom & 153 \\
& Significance & 0.000 \\
\hline
\end{tabular}

\subsection{Extraction and Naming of Factors}

Principal component analysis was used to extract the first five principal component factors with characteristic values greater than 1 ; the cumulative explanatory variance was $53.531 \%$ (see Table 5). The five factors reflect the information contained in the 18 original evaluation items. The load results for the rotated factors were calculated (see Table 6), and values for the expression of each factor were then obtained.

Table 5. Explanation of total variance.

\begin{tabular}{|c|c|c|c|c|c|c|c|c|c|}
\hline \multirow[b]{2}{*}{ Elements } & \multicolumn{3}{|c|}{ Initial Eigenvalue } & \multicolumn{3}{|c|}{ Extracted Sum of Squared Loads } & \multicolumn{3}{|c|}{ Rotating Load Sum of Squares } \\
\hline & Total & $\begin{array}{c}\text { Variance } \\
\text { Contribution } \\
\text { Rate }(\%)\end{array}$ & $\begin{array}{c}\text { Grand } \\
\text { Total (\%) }\end{array}$ & Total & $\begin{array}{c}\text { Variance } \\
\text { Contribution } \\
\text { Rate (\%) }\end{array}$ & $\begin{array}{c}\text { Grand } \\
\text { Total (\%) }\end{array}$ & Total & $\begin{array}{c}\text { Variance } \\
\text { Contribution } \\
\text { Rate (\%) }\end{array}$ & $\begin{array}{c}\text { Grand } \\
\text { Total }(\%)\end{array}$ \\
\hline 1 & 4.762 & 26.456 & 26.456 & 4.762 & 26.456 & 26.456 & 2.645 & 14.692 & 14.692 \\
\hline 2 & 1.476 & 8.197 & 34.653 & 1.476 & 8.197 & 34.653 & 1.997 & 11.095 & 25.787 \\
\hline 3 & 1.227 & 6.816 & 41.47 & 1.227 & 6.816 & 41.47 & 1.737 & 9.649 & 35.435 \\
\hline 4 & 1.157 & 6.429 & 47.899 & 1.157 & 6.429 & 47.899 & 1.63 & 9.054 & 44.49 \\
\hline 5 & 1.014 & 5.632 & 53.531 & 1.014 & 5.632 & 53.531 & 1.627 & 9.041 & 53.531 \\
\hline
\end{tabular}

Note: The extraction method used was principal component analysis. 
Table 6. Component matrix a after rotation.

\begin{tabular}{|c|c|c|c|c|c|c|}
\hline \multirow{2}{*}{\multicolumn{2}{|c|}{ Evaluation Item }} & \multicolumn{5}{|c|}{ Factor } \\
\hline & & \multirow{2}{*}{$\begin{array}{l}\mathbf{1} \\
0.758\end{array}$} & \multirow{2}{*}{$\begin{array}{l}2 \\
-\end{array}$} & \multirow{2}{*}{$\begin{array}{l}3 \\
-\end{array}$} & \multirow{2}{*}{$\begin{array}{l}4 \\
-\end{array}$} & \multirow{2}{*}{$\begin{array}{l}5 \\
-\end{array}$} \\
\hline X14 & A sense of layers in the planting & & & & & \\
\hline X11 & Space-separating function of plants & 0.661 & - & - & - & - \\
\hline X18 & Sense of space and openness & 0.653 & - & - & - & - \\
\hline X16 & $\begin{array}{l}\text { Coordination between plants and } \\
\text { surrounding environment }\end{array}$ & 0.48 & - & - & - & - \\
\hline X12 & Providing shade & - & 0.687 & - & - & - \\
\hline X15 & Variety of plant species & - & 0.659 & - & - & - \\
\hline X02 & Foliage plants & - & 0.608 & - & - & - \\
\hline X17 & Creation of shapes of spaces & - & 0.451 & - & - & - \\
\hline X09 & Edible plants & - & - & 0.752 & - & - \\
\hline $\mathrm{X} 10$ & Medicinal properties of plants & - & - & 0.698 & - & - \\
\hline X06 & Exotic plants & - & - & 0.57 & - & - \\
\hline X05 & Climbing plants & - & - & - & 0.684 & - \\
\hline X08 & Native plants & - & - & - & 0.555 & - \\
\hline X04 & Fruit-bearing plants & - & - & - & 0.543 & - \\
\hline X01 & Ancient and famous trees & - & - & - & 0.398 & - \\
\hline X13 & Plants with cultural significance & - & - & - & 0.348 & - \\
\hline X07 & Aromatic plants & - & - & - & - & 0.754 \\
\hline X03 & Flowering plants & - & - & - & - & 0.578 \\
\hline
\end{tabular}

Notes: Extraction method; principal component analysis method. Rotation method: Kaiser standardized maximum variance method; a rotation was converged after 10 iterations.

Factor 1 included four evaluation items, with a factor loading above 0.48 , namely, X14, $\mathrm{X} 11, \mathrm{X} 18$ and X16, among which the item "layers in the planting arrangement in X14" had the highest value (0.758). These four projects included the layout of the plant landscape (and layering of the planting), the function of dividing the space, coordination with the surrounding environment and a sense of space and openness, so this group was named the "spatial structure" factor.

Factor 2 included four evaluation items with a factor loading above 0.451 : X12, X15, X02 and X17. Among these, the "providing shade function of X12 plants", "diversity of X15 plants" and "X02 leafy plants" had higher values (0.687, 0.659 and 0.608 , respectively). These four projects reflect the tourists' pursuit of fun and entertainment through the plant landscape, and the offering of a shady space for tourists to rest and play, so this group was named the "functional structure" factor.

Factor 3 included three evaluation items, with a factor loading above 0.57, namely, X09, X10 and X06, among which "edible X09 plants" and "medicinal X10 plants" had little difference ( 0.752 and 0.698 , respectively). These three items reflect the fact that, nowadays, people are concerned about their health and appreciate the edible and medicinal value of plants. These items were, therefore, grouped as those with a "utility" factor.

Factor 4 included five evaluation items with a factor loading above 0.348: X05, X08, X04, X01 and X13. Among them, the item "X05 with climbing plants" had the highest value (0.684). These five projects introduced different ornamental parts of plants, such as branches, fruits, historical value and cultural connotations, reflecting the diversity and specificity of the ornamental value of plants. This group was therefore named the "heritage characteristics" factor.

Factor 5 included two evaluation items with a factor loading above 0.578: X07 and X3. Among them, the item "X07 has aromatic plants" had the highest value (0.754). These two projects reflect the visitors' love of flowers and fragrant plants. Vision and smell are important sensory functions for human beings, so they were named the "sensory characteristics" factor. 


\subsection{Factor Analysis}

In the case of factor 1, "spatial structure", the factor loads for "layering in the plant arrangement", the "space-separating function of plants" and "sense of space and openness" were relatively high $(0.758,0.661$ and 0.653 , respectively). This shows that most tourists have high expectations in terms of the layout of plant landscapes in temple gardens; they pay attention to the interweaving of the plant landscape and space, and tend to have a sense of how spaces change [25]. The artistic effect formed by light and shadow and the plant landscape can increase the flexibility of the temple gardens. In the survey, it was found that visitors liked the open spaces, and the use of shrubs and other materials can create this effect.

In the case of factor 2, "functional structure", the factor loads for the "plants providing shade function", "plant diversity" and "leafy plants" were nearly the same $(0.687,0.659$ and 0.608 , respectively). This shows that tourists like diverse and interesting plants and comfortable spaces in which to conduct leisure activities. Most of the temple garden plants are evergreen [26], and Ginkgo biloba can be added at major landscape nodes to provide visual stimulation. In addition, Fujian province of China has a subtropical monsoon climate, with a lot of rain, high temperatures and strong ultraviolet radiation. The elderly and infants in particular need protection from hot weather, and shade from plants along roads and at key sites and rest facilities can help provide a relatively cool leisure environment [27].

In the case of factor 3: "utility plants", the factor loads for "edible plants" and "medicinal plants" were 0.752 and 0.698 , respectively. With the increasing convenience of social travel methods and the growing popularity of leisure and entertainment concepts, more and more tourists come to temple gardens-not only to participate in religious activities but also to experience the historic and cultural landscape, to engage in leisure and entertainment activities, and to enjoy the scenery. According to records, in the 1930s in the United Kingdom, gardens were officially recognized as a method of healing the body, which can also play a positive role in spiritual healing. Notably, an article by Roger Ulrich, a German behaviorist and landscape architect, described the positive influence of nature on those who are ill and convalescing. The therapeutic power of gardens is now widely recognized. They are not only a place for ornamental plants but can also be an educational landscape, displaying the medicinal properties of plants [28]. The age range of people who can benefit from gardens includes teenagers, the middle-aged and the elderly, and gardens and other natural spaces are increasingly valued by tourists. Some studies show that caring for plants is a suitable activity for infants and teenagers, and can help improve their observation skills, creative thinking and intellectual development; it can also have a certain educational significance. In terms of plant selection, it is important to choose relatively safe plants, such as those without thorns, avoiding flying catkins and opting for non-toxic, mosquito-repellent plants. Curcuma longa, Zingiber officinale, Pandanus odorus, Cinnamomum zeylanicum and Syzygiumaromaticum can be used [29] to ensure the safety of young people. Bright colors are also important, to attract children's interest. Common plants include Cinnamomum camphora, Eucalyptus citriodora Hook. F., Asparagus and Nepenthes mirabilis, etc. Plants suitable for young and middle-aged people can relieve stress and help lift their mood. Green leaves are the best for liver health. A flavone glucoside named saponarin has been extracted from young, green barley leaves. This flavonoid gives the typical green color to the leaves and demonstrates powerful antioxidant potencies, with therapeutic effects on various cancers and inflammations [30]. Other common plants include Albizia, Magnolia grandiflora and citrus, etc. Well-known citrus fruits include grapefruit, lemons, limes, mandarins and oranges. Citrus fruit oil has been reported to improve hepatotoxicity in chickens fed a diet containing aflatoxin, a potent hepatocarcinogen, showing reduced lesions of hydropic degeneration and bile duct hyperplasia in the liver [31]. Plants with health-giving properties that are particularly beneficial for older people include those which help enhance body function and support the respiratory system [32], and cardiovascular system. So, in terms of plant selection, bactericidal and granular plants are a good choice. Common plants include Lonicera japonica, Dendranthema morifolium and Podocarpus, etc. [33] 
In the case of factor 4, "heritage characteristics", the factor loads for "climbing plants", "native plants" and "fruit-bearing plants" were $0.684,0.555$ and 0.543 , respectively. This shows that visitors like it when the temple garden plant landscape includes a diversity of plant forms, while maintaining distinct regional characteristics. In the interview survey, some non-local tourists reported that they would prefer a plant landscape with local characteristics, reflecting the local cultural landscape, and which thus have a strong sense of place. In addition, this factor also included "ancient and famous trees" and "plants with cultural significance", which reflect the spiritual and cultural needs of contemporary tourists. Furthermore, ancient and famous trees, as witnesses to history, play a role in commemorating and popularizing science. Plant landscape designers can choose "five trees and six flowers", "four holy trees" and "four great flowers" in Buddhism, in specific plant configurations [34], to create a sense of place in temple gardens.

In the case of factor 5: "sensory characteristics", the factor load for "aromatic plants" was the highest (0.754). Aromatic plants have the effect of regulating emotions and can make people relax, but some can make people nervous and attract pests, playing a negative role [35]. In the landscape configuration of temple gardens, pines and cypress plants are often used to give tourists a sense of awe and distance. Therefore, in quiet and peaceful temple gardens, plants with bright flowers and fragrance can help tourists relax and can lift their mood; they can also enhance the interaction between temple landscape and tourists. In terms of plant selection, suitable choices would be Nelumbo and Frangipani, etc.

\section{Conclusions}

In today's society, urban temple gardens continue to be revered as places of religious significance. However, they have also become multifunctional urban green spaces, integrating religious activities, leisure and entertainment, tourism and historical and cultural experiences. Compared with busy modern life, temple gardens have a Zen, clean and serene aesthetic atmosphere [36]. The views of tourists, as the main users of temple gardens, should be taken into consideration during the design process, so that attractive landscapes can be created which meet their needs and wishes. In this study, factor analysis was used to obtain five major factors relevant to the construction of urban temple gardens: the design layout factor of the plant landscape, basic functional factors of the plant landscape, the health-giving properties of plants, the spiritual nature of the place, and the interaction between plants and people.

As China has come to pay more and more attention to the protection and construction of temple gardens, the design of plant landscapes has also become increasingly important. The planning and design of gardens based on the perceptions of tourists can enable more attractive plant landscapes to be created. The realization of sustainable development of temple garden plant landscapes has important practical significance for protection and development of the ecological environment. Having completed this study, the author's next step will be to use the five factors to evaluate and analyze the garden plant landscape of the Chongfu Temple, Chengtian Temple and other temples, in order to attract more tourists to experience and enjoy Chinese religious culture.

Author Contributions: Data Curation, Y.Z., Y.C. and J.L.; methodology, Y.Z.; software, Y.C. and J.L.; resources, Y.Z.; formal analysis, J.L.; writing—original draft preparation, Y.Z.; writing-review and editing, Y.C. All authors have read and agreed to the published version of the manuscript.

Funding: This research received no external funding.

Institutional Review Board Statement: This research was approved by the Institution Review Board of authors' university.

Informed Consent Statement: Informed consent was obtained from all subjects involved in the study.

Data Availability Statement: The data used to support the findings of this study are available from the corresponding author upon request.

Conflicts of Interest: The authors declare no conflict of interest. 


\section{Appendix A}

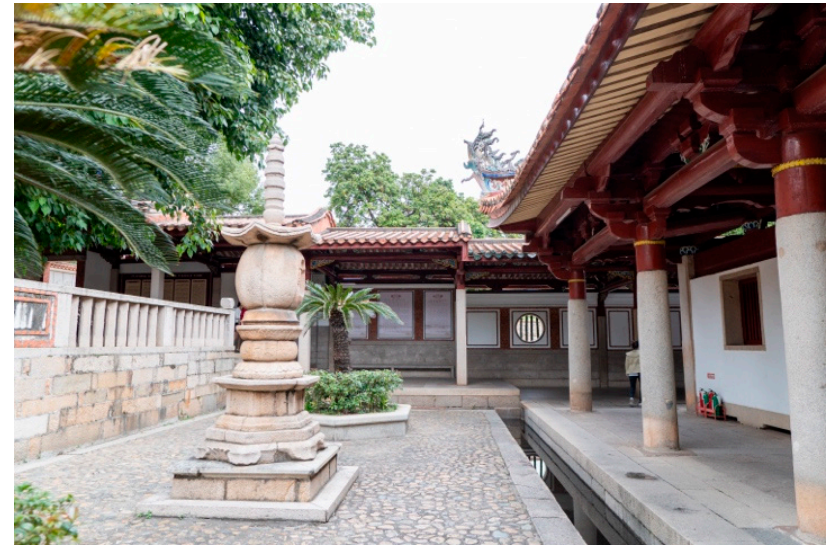

The Temple Space

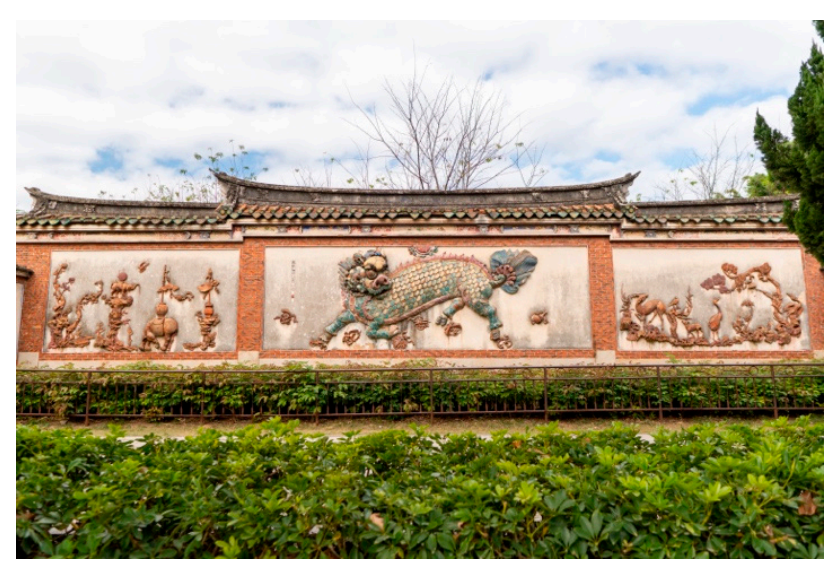

Porcelain carving and relief art

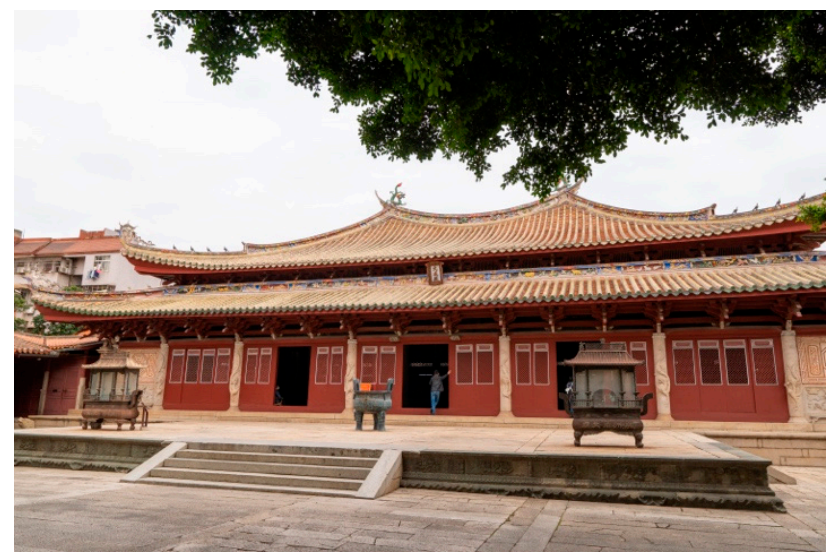

The Dacheng Hall

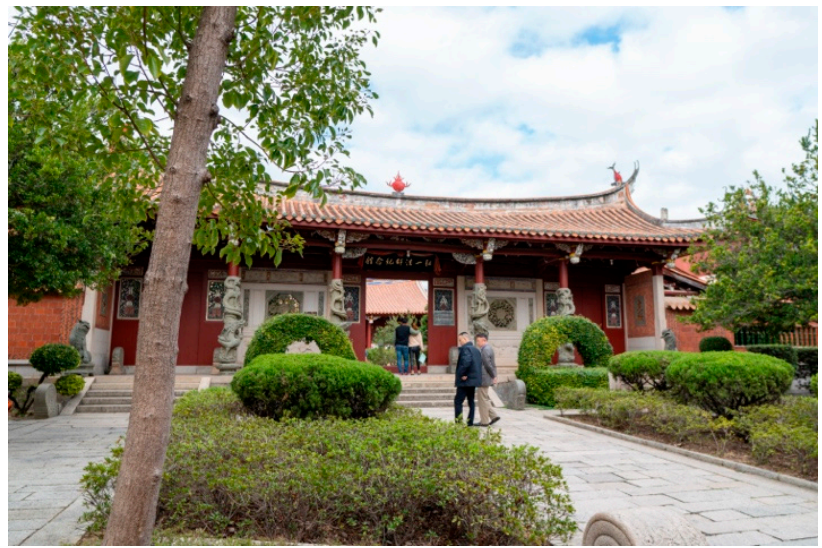

The Hongyi Master Memorial Hall

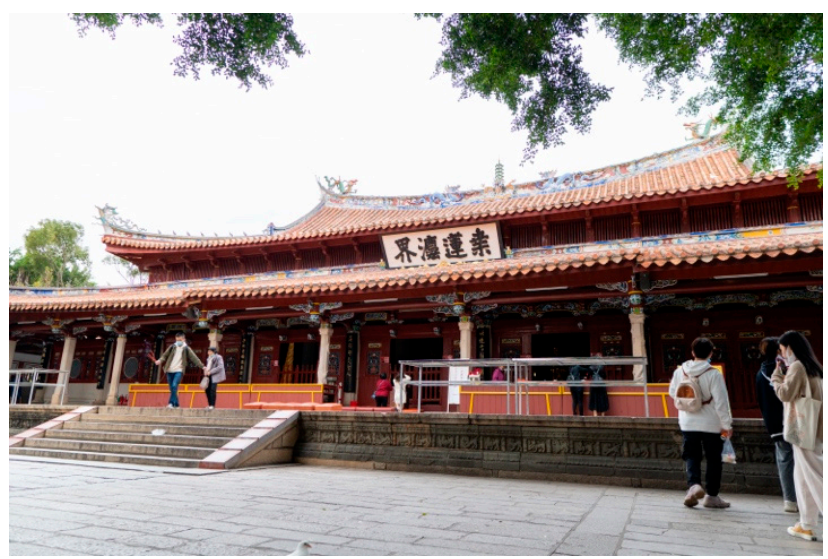

The Daxiong Hall

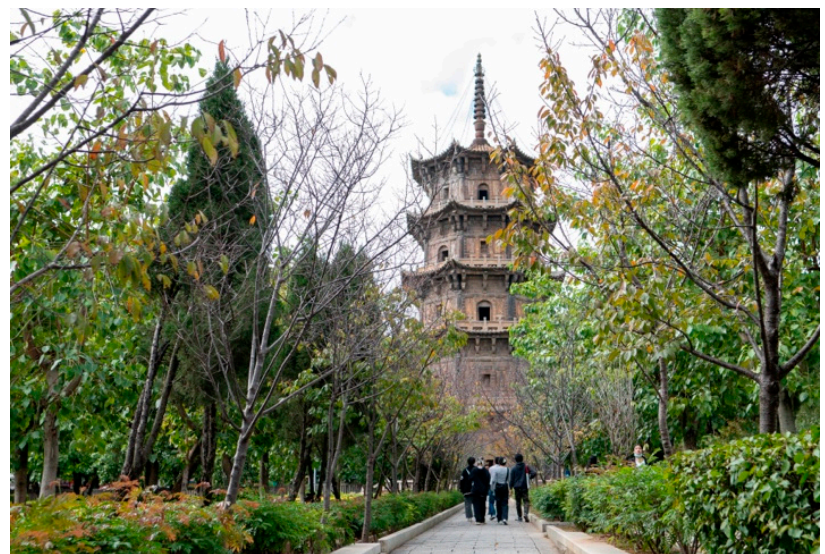

The Renshou Tower

Figure A1. The Spatial Landscape of Kaiyuan Temple. 


\section{Appendix B}

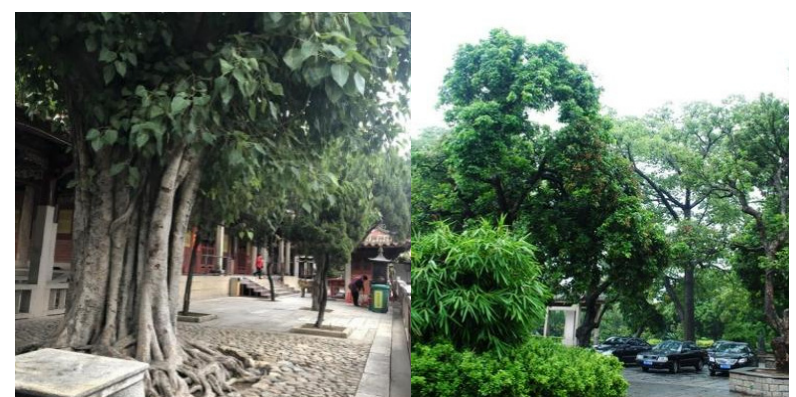

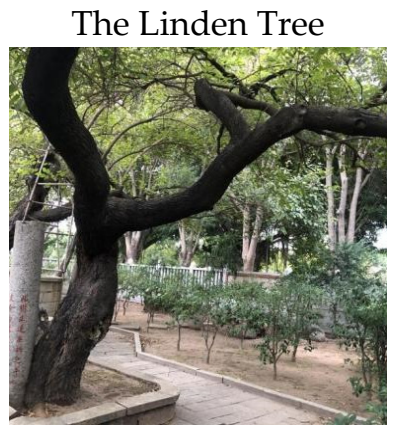

The mulberry Tree
The Longan Tree

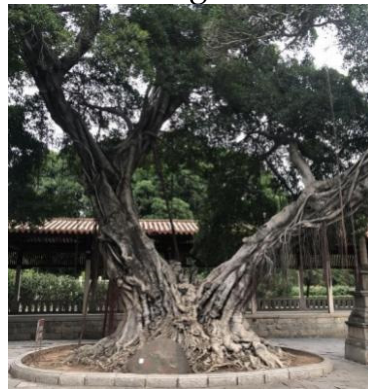

The Banyan Tree

Figure A2. Plant landscape in Kaiyuan Temple.

\section{Appendix C}

Table A1. Questionnaire survey of plant landscape indicators.

\begin{tabular}{|c|c|c|c|c|c|c|}
\hline $\begin{array}{c}\text { The Serial } \\
\text { Number }\end{array}$ & Name of Factor & $\begin{array}{c}\text { Strongly } \\
\text { Agree } \\
\text { (5 Points) }\end{array}$ & $\begin{array}{c}\text { Agree } \\
\text { (4 Points) }\end{array}$ & $\begin{array}{c}\text { Neutral } \\
\text { (3 Points) }\end{array}$ & $\begin{array}{l}\text { Disagree } \\
\text { (2 Points) }\end{array}$ & $\begin{array}{l}\text { Strongly } \\
\text { Disagree } \\
\text { (1 Point) }\end{array}$ \\
\hline 1 & Ancient and famous trees & & & & & \\
\hline 2 & Flowering plants & & & & & \\
\hline 3 & Growth of plants & & & & & \\
\hline 4 & Leafy plants & & & & & \\
\hline 5 & Seasonal phase of plants & & & & & \\
\hline 6 & Fruit-bearing plants & & & & & \\
\hline 7 & Perspective of plant space & & & & & \\
\hline 8 & Climbing plants & & & & & \\
\hline 9 & Health status of plants & & & & & \\
\hline 10 & Exotic plants & & & & & \\
\hline 11 & Fragrant plants & & & & & \\
\hline 12 & Native plants & & & & & \\
\hline 13 & The specificity of plant leaf shape & & & & & \\
\hline 14 & Edible plants & & & & & \\
\hline 15 & Medicinal plants & & & & & \\
\hline 16 & Plants with a space-separating function & & & & & \\
\hline 17 & Plants providing shade & & & & & \\
\hline 18 & Wind resistance of plants & & & & & \\
\hline 19 & Plants with cultural significance & & & & & \\
\hline 20 & Persistence of plant effects & & & & & \\
\hline 21 & Color of plants & & & & & \\
\hline 22 & A planting layout that creates a sense of layers & & & & & \\
\hline 23 & Stability of plants & & & & & \\
\hline 24 & Plant species diversity & & & & & \\
\hline 25 & $\begin{array}{l}\text { Coordination between plants and the surrounding } \\
\text { environment }\end{array}$ & & & & & \\
\hline 26 & Plant green vision & & & & & \\
\hline 27 & Texture of plants & & & & & \\
\hline 28 & Creation of spaces and shapes & & & & & \\
\hline 29 & Sense of space and openness & & & & & \\
\hline 30 & The richness of plant contour & & & & & \\
\hline
\end{tabular}




\section{Appendix D}

Table A2. Evaluation Questionnaire for Plant Landscape Construction Factors.

\begin{tabular}{|c|c|c|c|c|c|}
\hline Evaluation Factor & $\begin{array}{c}\text { Strongly } \\
\text { Agree } \\
\text { (5 Points) }\end{array}$ & $\begin{array}{c}\text { Agree } \\
\text { (4 Points) }\end{array}$ & $\begin{array}{c}\text { Neutral } \\
\text { (3 Points) }\end{array}$ & $\begin{array}{c}\text { Disagree } \\
\text { (2 Points) }\end{array}$ & $\begin{array}{l}\text { Strongly } \\
\text { Disagree } \\
\text { (1 Point) }\end{array}$ \\
\hline $\begin{array}{l}\text { Do you think there should be ancient and famous trees in the plant } \\
\text { landscape in Kaiyuan Temple } \\
\text { Do you think there should be foliage plants in the plant landscape } \\
\text { of Kaiyuan Temple } \\
\text { Do you think there should be flower plants in the plant landscape } \\
\text { of Kaiyuan Temple } \\
\text { Do you think there should be fruit viewing plants in the plant } \\
\text { landscape in Kaiyuan Temple } \\
\text { Do you think there should be climbing plants in the plant } \\
\text { landscape of Kaiyuan Temple } \\
\text { Do you think there should be exotic plants in the plant landscape in } \\
\text { Kaiyuan Temple } \\
\text { Do you think there should be aromatic plants in the plant } \\
\text { landscape in Kaiyuan Temple } \\
\text { Do you think there should be native plants in the plant landscape } \\
\text { in Kaiyuan Temple } \\
\text { Do you think the plant landscape in Kaiyuan Temple should pay } \\
\text { attention to the edibleness of plants } \\
\text { Do you think the plant landscape in Kaiyuan Temple should pay } \\
\text { attention to the medicinal properties of plants } \\
\text { Do you think that the plant landscape in Kaiyuan Temple should } \\
\text { pay attention to the space separation function of plants } \\
\text { Do you think that the plant landscape in Kaiyuan Temple should } \\
\text { pay attention to the shading function of plants } \\
\text { Do you think the plant landscape construction in Kaiyuan Temple } \\
\text { should pay attention to the cultural nature of plant configuration } \\
\text { Do you think that the plant landscape in Kaiyuan Temple should } \\
\text { pay attention to the sense of hierarchy of plant layout } \\
\text { Do you think that the plant landscape in Kaiyuan Temple should } \\
\text { pay attention to the diversity of plant species } \\
\text { Do you think that the plant landscape in Kaiyuan Temple should } \\
\text { pay attention to the coordination between plants and the } \\
\text { surrounding environment } \\
\text { Do you think that the plant landscape in Kaiyuan Temple should } \\
\text { pay attention to the recreational nature of space shaping } \\
\text { Do you think that the plant landscape in Kaiyuan Temple should } \\
\text { pay attention to the openness of space vision }\end{array}$ & & & & & \\
\hline
\end{tabular}

\section{References}

1. Chen, B. Study on the Configuration of Garden Plants in Hangzhou West Lake-Plant Community Function, Species Composition and Case Analysis; Zhejiang University: Hangzhou, China, 2006. (In Chinese)

2. Diao, K. On the layout of plant landscape. Chin. Landsc. Archit. 2001, 1, 51-52. (In Chinese)

3. Zhou, Z.Y. History of Chinese Classical Gardens, 3rd ed.; Tsinghua University: Beijing, China, 2010. (In Chinese)

4. Li, C.J.; Jia, P.Y.; Dong, L. Program and method of plant landscape planning and design in landscape architecture. Chin. Landsc. Archit. 2014, 30, 93-99. (In Chinese)

5. Chambers, W. A Dissertation on Oriental Gardening; Kessinger Publishing, LLC: Whitefish, MT, USA, 2010. Available online: https: //books.google.com.sg/books/about/A_Dissertation_on_Oriental_Gardening.html?id=Dy1cAAAAQAAJ\&redir_esc=y (accessed on 12 January 2022).

6. Henri, C. China in the French Perspective in the 18th Century; Shanghai Bookstore Publishing House: Shanghai, China, 2006.

7. Keswick, M.; Jencks, C.; Hlard, A. The Chinese Garden: History, Art and Architecture; Harvard University Press: Cambridge, MA, USA, 2003.

8. Liang, S.C. Chinese Architecture and Art; Contemporary World Press: Beijing, China, 2006. (In Chinese)

9. Ding, Z.G.; Fu, D.L. On space Composition of Buddhist Temple Gardens-A Case Study of Puji Temple, Fayu Temple and Huiji Temple. Zhejiang For. Sci. Technol. 2006, 6, 14-18. (In Chinese)

10. Liang, S.C. Talking about Architecture; Contemporary World Press: Beijing, China, 2006. (In Chinese)

11. Zhuang, Y.G. Style and School; Baihua Literature and Art Publishing House: Tianjin, China, 2005. (In Chinese)

12. Zhou, W.Q. A Study on the Landscape of Chinese Buddhist Temple Gardens. Guangdong Landsc. Archit. 2007, 4, 5-7. (In Chinese)

13. Zhao, G.H. The Garden Environment of Chinese Temples; Beijing Tourism Publishing House: Beijing, China, 1987. (In Chinese) 
14. Boifava, B.; Marx, R.B. Roberto Burle Marx's Cidade Parque. J. Landsc. Archit. 2020, 15, 74-89. [CrossRef]

15. Brasete, M.F. Theophrastus. History of Plants. Agora-Estud. Class. Debate 2017, 19, 491-494.

16. Feng, X.B. Research on Kaiyuan Temple in Quanzhou; Hebei Normal University: Hebei, China, 2012. (In Chinese)

17. Yang, W.Q. A Brief Talk on the Value and Status of Kaiyuan Temple in Quanzhou. J. Longyan Teach. Coll. 2000, 2, 61-66. (In Chinese)

18. Hui, W.Y. Research on Tourists' Perception of Landscape Elements in Suzhou Pingiang Historical and Cultural District Based on Intertextuality Interpretation; Suzhou University: Jiangsu, China, 2020. (In Chinese)

19. Dalkey, N.; Helmer, O. An experimental application of the Delphi methods to the use of experts. Manag. Sci. 1963, 9, 458-467. [CrossRef]

20. Feng, X.T. Questionnaire Design in Social Survey; Tianjin People's Publishing House: Tianjin, China, 2002. (In Chinese)

21. Zou, D.J.; Lloyd, J.E.V.; Baumbusch, J.L. Using SPSS to Analyze Complex Survey Data: A Primer. J. Mod. Appl. Stat. Methods 2019, 18, 2-5. [CrossRef]

22. Zhang, J.H. Investigation analysis in Planning and Design 15 -Factor Analysis. Chin. Landsc. Archit. 2004, 9, 76-81. (In Chinese)

23. Singh, S.K.; Sachdeva, H.; Joon, H.; Narang, M. Water Quality Assessment of a Water Body using Principal Component Analysis -Sanjay Lake, New Delhi, India. Asian J. Water Environ. Pollut. 2020, 17, 23-29. [CrossRef]

24. Zhang, W.T.; Dong, W. SPSS Advanced Course of Statistical Analysis; Higher Education Press: Beijing, China, 2002. (In Chinese)

25. Wang, R. A Rational Planning Method for the Spatial Layout of Natural Plant Landscape in Gardens. In Proceedings of the 2019 China Erya Literature and Huachai Art Symposium Proceedings, Beijing, China, 24 August 2019; pp. 45-46. (In Chinese).

26. Liu, F.D.; Jiang, J.H.; Hu, G. Analysis on the Arrangement Law of Garden Plants in Chinese Temples. J. ZheJiang Sci-Tech Univ. (Soc. Sci. Ed.) 2019, 42, 503-511. (In Chinese)

27. Gungor, B.S.; Ozanguc, K.C. Leading effect of visual characteristics for functional uses of green spaces. J. Fac. For. Istanb. Univ. 2016, 66, 379-390.

28. Pudelska, K.; Dudkiewicz, M.; Durlak, W.; Parzymies, M. An Importance of the former and present therapeutic gardens. Acta Sci. Pol. Form. Circumiectus 2016, 15, 125-137. [CrossRef]

29. Tisgratog, R.; Sanguanpong, U.; Grieco, J.P.; Ngoen-Kluan, R.; Chareonviriyaphap, T. Plants traditionally used as mosquito repellents and the implication for their use in vector control. Acta Trop. 2016, 57, 136-144. [CrossRef] [PubMed]

30. Kamiyama, M.; Shibamoto, T. Flavonoids with Potent Antioxidant Activity Found in Young Green Barley Leaves. J. Agric. Food Chem. 2012, 60, 6260-6267. [CrossRef]

31. Ortatatli, M.; Oguz, H.; Hatipoglu, F.; Karaman, M. Evaluation of pathological changes in broilers during chronic aflatoxin (50 and $100 \mathrm{ppb}$ ) and clinoptilolite exposure. Res. Vet. Sci. 2005, 78, 61-68. [CrossRef]

32. Abdulrahman, M.D.; Ali, A.M.; Khandaker, M.M.; Fatihah, H.N.N.; Mat, N. Review on traditional knowledge and utilization of medicinal plants. Biosci. Res. 2019, 16, 3298-3313.

33. Li, H.W. Classification and application of garden health plants. Consum. Guide 2008, 10, 186. (In Chinese)

34. Yan, X.J.; Zhou, Y.L.; Li, S.S. Common plants in Buddhist temples. Chin. J. Biol. 2013, 48, 7-11. (In Chinese)

35. Wang, C.L.; Hu, Z.H.; Shen, H.; Leng, P.S. Health care effects of aromatic plant volatiles. North. Hortic. 2015, 15, 171-177. (In Chinese)

36. Wei, L.; Wang, L. Research on integral Protection of Urban Temple Gardens-A Case study of Guodusi Temple in Wuhan city. J. Huazhong Agric. Univ. 2016, 35, 50-54. (In Chinese) 